\title{
La investigación sobre el Antiguo Egipto en Brasil: balance, retos y perspectivas
}

Marcia S. Vasques*

Recibido:

28 de abril de 2019

Aceptado:

5 de diciembre de 2019

\section{Resumen}

Nuestro objetivo en este artículo es explicar el surgimiento de la Egiptología en Brasil, sus caminos de investigación, desdoblamientos e investigaciones futuras. Los estudios realizados en el campo de la Egiptología tuvieron como foco original a la familia imperial brasileña, lo cual demostró interés por los artefactos egipcios en la época en que era común la práctica del coleccionismo y nacían las ciencias del siglo XIX. Como resultado de dicho interés, los primeros objetos del Antiguo Egipto llegaron a Río de Janeiro y fueron depositados en el Museo Nacional de la Quinta da Boa Vista. Otro foco de estudio se originó en la Universidad de São Paulo, por estar situada en la ciudad que constituye el polo económico de Brasil y en la cual se realiza la mayor inversión en el área de la investigación científica. En nuestra opinión, es posible trazar una genealogía de la Egiptología brasileña a partir de dos ejes: Río de Janeiro, con el Museo Nacional y la Universidad Federal Fluminense y la Universidad de São Paulo. Fue a partir de estos centros formadores de investigadores que el área de la Egiptología se expandió hacia otras regiones del país.

\section{The research on Ancient Egypt in Brazil: balance, challenges, and perspectives}

\begin{abstract}
Our aim in this paper is to explain the emergence of Egyptology in Brazil, the linesof research, the ramifications, and future researches. Egyptology studies originally focused on the Brazilian imperial family, and demonstrated the interest in Egyptian artifacts during times when artifact collecting activities were common and the 19th-century sciences were born. As a result, the first objects from Ancient Egypt arrived in Rio de Janeiro and were sent to the National Museum of Quinta da Boa Vista. Another center of study started at the University of São Paulo, as it is located in the city that was the Brazilian economic center, with the biggest investment in scientific research. We suggest that a genealogy of Brazilian Egyptology can be traced, departing from two pillars: Rio de Janeiro, with the National Museum, the Federal Fluminense University, and the University of São Paulo. From these researchers training centers, Egyptology spread to other regions in the country.
\end{abstract}

Palabras clave

Egiptología Historia

Arqueología Coleccionismo Museo Nacional Universidad

Keywords Egyptology History Archeology Collecting National Museum University

*Departamento de História, Centro de Ciências Humanas, Letras e Artes (CCHLA), Universidade Federal do Rio Grande do Norte (UFRN). Av. Senador Salgado Filho 300o, Campus Universitário Lagoa Nova (CP 59.078-970), Natal, Rio Grande do Norte, Brasil. E-mail: vasquesms@gmail.com 


\section{Introducción}

$\mathrm{Al}$ reflexionar sobre el surgimiento de la Egiptología en Brasil, nos encontramos con una constatación instigante: en cierto modo la Egiptología, esto es, el estudio del Antiguo Egipto, llegó a Brasil de manera concomitante con el interés y el atractivo que constituyó el Antiguo Egipto para Europa en los siglos XVIII y XIX. La monarquía brasileña seguía de alguna manera la moda europea y había adoptado la práctica del coleccionismo, propia de la nobleza del Viejo Continente. La presencia de artefactos egipcios en Brasil se asocia a la monarquía reinante, inicialmente portuguesa y luego brasileña, cuando Don Pedro I abdicó del trono en favor de su hijo todavía menor de edad, Don Pedro II, en 1831. Esta monarquía de los trópicos desentonaba y contrastaba con las repúblicas existentes en América y constituía uno de los rasgos a los que debía Brasil su singularidad en el continente. Aunque Pedro II tuviera un interés por la ciencia, entonces todavía en estado embrionario en el país, el establecimiento de una carrera en Egiptología en Brasil sólo se produjo al final del siglo XX.

El recorrido de la Egiptología en el medio académico estuvo vinculado a la Historia Antigua y a la Arqueología Clásica y se destacaron como polos las ciudades de Río de Janeiro y São Paulo. Río de Janeiro, como ciudad sede de la capital del Imperio brasileño y de la República hasta su sustitución por Brasilia, en 1960, fue el polo de desarrollo de dos universidades importantes, la Universidad Federal de Río de Janeiro -institución a la que se destinó el Museo Nacional de la Quinta da Boa Vista, antiguo palacio imperial de São Cristóvão- y la Universidad Federal Fluminense, cuyo desarrollo en el área de la Egiptología se materializó, en gran parte, gracias al interés y la dedicación de Ciro Flamarion Santana Cardoso. Otro polo brasileño de formación en Historia Antigua y en Arqueología Clásica fue la Universidad de São Paulo. De sus grupos de graduados egresaron investigadores que se establecieron en los programas de postgrado de otros estados, entre ellos Antonio Brancaglion Jr., quien al ingresar como profesor en el Museo Nacional, se dedicó al estudio de su colección egipcia. Nuestro objetivo en este artículo es explicar, de manera concisa, el surgimiento de la Egiptología en Brasil, sus trayectorias académicas y señalar nuevos caminos y perspectivas de este campo de estudio.

\section{El Museo Nacional de la Quinta da Boa Vista}

Desde la época del Renacimiento, Europa experimentó una glorificación de lo clásico y del arte clásico. Muchas obras, esculturas, columnas y artefactos de origen griego y romano se utilizaron como elementos decorativos y como objetos de colección (Carlan y Funari, 2010). Las casas reales europeas y su nobleza practicaban el coleccionismo de obras de arte y de artefactos arqueológicos. La práctica coleccionista, vinculada al interés por el pasado clásico, propició una verdadera búsqueda o caza del tesoro, en pos de los artefactos que pudieran servir a las colecciones privadas, pero también favoreció la aparición de elementos que se transformaron en el meollo de la arqueología clásica naciente, como las copias de las inscripciones antiguas, los dibujos que reproducían los monumentos y los objetos considerados de valor para la historia del arte. El coleccionismo también estuvo presente en Brasil entre la familia imperial reinante. La propia emperatriz Teresa Cristina, esposa de D. Pedro II, princesa del reino de las Dos Sicilias, trajo a Brasil como dote objetos provenientes de Pompeya y Herculano, las ciudades enterradas por la erupción del Vesubio en el año 79 d.C., las cuales fueron excavadas a finales del siglo XVIII y principios del XIX.

Los estudios clásicos sirvieron como modelo para el desarrollo de la Egiptología y de la Asiriología durante el siglo XIX. Hasta entonces se conocían las antiguas civilizaciones de Egipto y del Oriente Próximo a través de referencias bíblicas y de las obras de los autores griegos y latinos. Una investigación más sistemática sobre el Antiguo Egipto se inició 
con la expedición de eruditos franceses organizada por Napoleón Bonaparte durante su invasión de Egipto en 1798. El resultado de estos trabajos se publicó en varios volúmenes conocidos como la Description de l'Égypte, hito en el inicio de la Egiptología como una ciencia junto con el desciframiento de los jeroglíficos por Jean-François Champollion en 1822 (Ikram, 2009). La propia piedra de Rosetta, una de las claves para descifrar la escritura egipcia, fue encontrada por un militar de Bonaparte, el capitán Pierre-François Bouchard, en Rosetta, en el delta del Nilo (Donadoni, Curto y Roveri, 1990).

Al mismo tiempo en que Europa se consolida con la formación de los estados nacionales, Oriente le servía, en cierto modo, como su otro antagónico que la seducía y la instigaba. El fenómeno del Orientalismo, abordado por Edward Said (1990), es un discurso construido sobre el Oriente como un campo de estudio que se desarrolla en la academia. Junto con los departamentos coloniales, responsables de la administración colonial, la antropología y la arqueología eran utilizadas para la realización de exposiciones y para el aprovisionamiento del acervo de museos europeos. Hasta su consolidación como ciencia, la Egiptología convivía con la egiptomanía, la moda por el Antiguo Egipto y el Oriente que de manera general invadió Europa. El deseo por los objetos que adornarían las colecciones europeas alentó los viajes de muchos exploradores a Egipto, entre ellos Giovanni Belzoni y Bernardino Drovetti, cónsul general francés. El saqueo de las tumbas se redujo sólo después de que Auguste Mariette fuera nombrado curador de los monumentos egipcios en 1858 (Trigger, 2004).

Los primeros artefactos egipcios llegaron a Brasil como consecuencia de esta fiebre por el Antiguo Egipto, de esta fase exploratoria del comercio de antigüedades. El emperador Don Pedro I adquirió las primeras piezas en una subasta realizada en una plaza pública (Bakos, 2009). En 1824, el comerciante de antigüedades Nicolau Fiengo arribó a Río de Janeiro con objetos egipcios y momias para vender. Hay más de una versión para explicar la llegada de Fiengo a la capital imperial. En una de ellas se cuenta que su barco originalmente se destinaba a Buenos Aires, pues las piezas habían sido encargadas por el gobernador, Juan Manuel Ortiz de Rosas, tal vez bajo órdenes del propio presidente argentino, Bernardino Rivadavia, fundador de la Universidad de Buenos Aires (Brancaglion Jr., 2013). Probablemente debido a la inestable situación política en Argentina, el barco se dirigió hacia Río de Janeiro, donde Fiengo subastó las piezas. En la segunda versión, Fiengo se dirigió a Río de Janeiro tras dejar Argentina y por temor a una epidemia de fiebre amarilla en la ciudad, decidió deshacerse rápidamente del cargamento que le quedaba, por lo que subastó las piezas. Estas piezas - primeras egipcias de Brasil— fueron adquiridas por Don Pedro I en 1827, pagadas en tres plazos y donadas al Museo Real, que había sido fundado por el rey Don João VI en 1818, diez años después de la llegada de la familia real portuguesa a Brasil. La carga de Fiengo venía de Marsella y probablemente contenía objetos comprados por éste a Giovanni Baptista Belzoni, el explorador italiano responsable de numerosos descubrimientos en Egipto, especialmente en la región tebana.

En el caso brasileño, un monarca en especial, Don Pedro II, representa bien esta época de transición entre el coleccionismo practicado por la élite y la preocupación con las ciencias, que se estaban consolidando en el siglo XIX. La educación humanista que recibió lo formó como un emperador preocupado con la "civilización", un emperador según los moldes ilustrados, letrado, culto, frecuentador de las ferias internacionales y deseoso de conocer el mundo (Lemos, 2014). A los veinticuatro años de edad Don Pedro II ingresó al IHGB - Instituto Histórico y Geográfico Brasileño-, espacio que compartía con literatos como Joaquim Manoel de Macedo, Gonçalves Magalhães, Gonçalves Dias y Adolfo Varnhagem, uno de los fundadores de la historiografía brasileña (Schwarcz, 2009). La participación efectiva del monarca en el Instituto se dio a partir de 1840, cuando se preocupó por distribuir becas de estudio para que los jóvenes artistas y científicos fueran a estudiar a Europa. Su preocupación era también la unificación nacional, la creación de 
1. La destrucción del Museo Nacional fue una gran pérdida para la ciencia brasileña, latinoamericana y mundial. La colección egipcia del Museo Nacional fue la más grande de Latinoamérica. Con el incendio, se creía que la colección se había perdido por completo. Sin embargo, en el proceso de rescate, se recuperaron 300 piezas. Para más información ver:

http://www.museunacional.ufrj.br/ destaques/balan\%C $3 \%$ A70_resgatehtml.html (Museu Nacional, una identidad basada en el modelo del Romanticismo, que asoció la imagen del nativo a la identidad nacional (Schwarcz, 1998).

D. Pedro II hizo dos viajes a Egipto, uno en 1871 y el segundo en 1876. Los viajes del emperador fueron registrados en fotografías tomadas con daguerrotipos, una innovación tecnológica de la época. En una de estas, fechada en 1871, la comitiva real está en el borde de las pirámides, acompañada por François-Auguste Mariette (Silva, 2017). En su segundo viaje a Egipto el emperador recibió como regalo del jedive Ismail Pachá, nieto de Mohammed Alí, el sarcófago con la momia de Sha-Amun-em-Su, sacerdotisa cantora del templo de Amón (Dinastía XXIII, ca. 750 a.C.), una momia representativa del acervo egipcio del Museo Nacional de la Quinta da Boa Vista, que se mantuvo en el despacho del emperador hasta la Proclamación de la República. Además de coleccionar artefactos, la erudición de D. Pedro II y su interés por la Egiptología se hacen evidentes en sus estudios de la escritura jeroglífica y de la cultura egipcia. Los libros y catálogos del emperador forman parte del conjunto de bienes de la biblioteca del Museo Nacional. Entre estos se cuentan importantes publicaciones del siglo XIX como la voluminosa obra Description de l'Égypte, o Atlas de l'Histoire de l'Art égyptienne de autoría de Prisses d'Avennes, tres obras de Jean-François Champollion: Panthéon Égyptien - Collection des Personnages Mythologiques de l'Ancienne Égypte; Monuments de l'Égypte et Nubie y Grammaire Égyptienne; y, de autoría de Vivant Denon, Voyage dans la Basse et la Haute Égypte.

El Museo Real, instituido por el rey Don João VI, se ubicaba en el Campo de Santana. Con la Proclamación de la República, en 1889, fue trasladado al palacio imperial de la Quinta da Boa Vista en el barrio de São Cristóvão. El Palacio São Cristóvão, como era conocido, sirvió como vivienda de la familia real portuguesa de 1808 a 1821 y de la familia imperial brasileña de 1822 a 1889, cuando se proclamó la República. Se convirtió en museo en 1892. En 1946, el Museo fue incorporado a la Universidad de Brasil, futura Universidad Federal de Río de Janeiro. Su colección tenía más de 20 millones de artículos, incluyendo los artefactos y las momias egipcias, la colección de Pompeya y Herculano de la emperatriz Teresa Cristina y el fósil prehistórico Luzia, el más antiguo de Brasil. Después del incendio del 2 de septiembre de 2018, que dio lugar a la destrucción del palacio y de la mayor parte de su acervo, hubo un gran debate en la sociedad brasileña sobre el tema de las colecciones de los museos y las políticas públicas de conservación. Los escombros del Museo Nacional, desde su incendio, están siendo excavados por un equipo de arqueólogos del propio sector de arqueología del Museo. Algunos artefactos han sido recuperados, pero todavía es difícil decir qué es exactamente lo que se perdió, ya que se trató de un incendio de gran magnitud ${ }^{1}$.

El Museo Nacional poseía alrededor de 700 piezas egipcias y seis momias, cuatro de adultos y dos de niños. Gran parte del acervo egipcio fue constituido en la época imperial. Pero posteriormente la colección creció por medio de compras y de donaciones de particulares. Sin embargo, faltaban registros de la mayoría de las piezas. Muchos sarcófagos, con sus respectivas momias, probablemente vinieron de la región de Tebas, debido a su estilo y formato típicos del material arqueológico proveniente de Tebas, un hecho que también corresponde a la hipótesis de que pueden proceder de las excavaciones llevadas a cabo en el área por Belzoni. Brancaglion Jr. (2005) cita, entre ellos, especialmente los ataúdes de los funcionarios tebanos Hori, Harsiese y Pestjef. También pertenecía a la región tebana una estela del período grecorromano dedicada al dios Montu. Otras estelas que formaban parte de la colección procedían de Abidos, al norte de Tebas. Eran estelas votivas confeccionadas por familias que las dedicaban al dios principal de Abidos, Osiris, junto con su esposa Isis y su hijo, Horus, formando la típica tríada familiar egipcia. Estas estelas habían sido colocadas en capillas votivas dispuestas en la vía procesional que daba acceso al templo de Osiris en Abidos, principal sede de culto de este dios en Egipto. 
Aunque tenga en su origen el acervo de la familia imperial y la herencia humanista de D. Pedro II, la colección egipcia del Museo Nacional no siempre contó con un curador especializado, debido a la propia dificultad de la educación universitaria en Brasil en el área de la Egiptología. De 1912 a 1938 la colección egipcia estuvo bajo el cuidado de Alberto Childe, de origen ruso, quien aprendió a leer la escritura egipcia por su cuenta y asistió a las clases de Gaston Maspero en el Collège de France, en París. Según Brancaglion Jr. (2005), en 1912 Alberto Childe fue nombrado Conservador de Arqueología en el Museo Nacional y, en 1919, publicó la Guia das Collecções de Arheologia Clássica, un estudio realizado del acervo egipcio y clásico del museo. Un estudio sistemático de la colección egipcia del Museo fue llevado a cabo solo en 1990 por Kenneth Kitchen, egiptólogo británico, con la colaboración de Maria da Conceição Beltrão, entonces curadora del acervo. Su trabajo fue publicado con el título de Catálogo da Coleção do Egito Antigo existente no Museu Nacional do Rio de Janeiro/Catalogue of the Egyptian Collection in the National Museum, Rio de Janeiro (Brancaglion Jr., 2005).

Antonio Brancaglion Júnior ingresó como profesor investigador en el Museo Nacional en el año 2002. Los estudios del acervo egipcio de la institución se centraron, a partir de entonces, en dos frentes de investigación: el primero con respecto al estudio de momias humanas y animales en un abordaje multidisciplinario que se valió de la anatomopatología y la arqueología (lo que permite la recogida de muestras de ADN, polen, insectos, hongos, resinas y pigmentos), en tanto que el segundo fue desarrollado en el Laboratorio de Procesamiento de Imagen Digital (LAPID-Museo Nacional) con la digitalización de los objetos y su replicación virtual o física.

La investigación en Egiptología en el Museo Nacional está vinculada al SESHAT (2020) - Laboratorio de Egiptología del Museo Nacional (https://seshat.museunacional.ufrj. br/), que reúne a investigadores y estudiantes del área de Egiptología. Desde 2013, el Programa de Postgrado en Arqueología del Museo Nacional promueve la SEMNA Semana de Egiptología, que siempre tiene lugar la primera semana de diciembre en homenaje al cumpleaños de D. Pedro II (2 de diciembre), patrón de la Egiptología brasileña. Además de la Egiptología desarrollada en Brasil, el Museo Nacional también tiene una misión conjunta con Argentina en los estudios de la tumba de Neferhotep (TT49), en conjunto con María Violeta Pereyra, profesora de la Universidad de Buenos Aires (UBA).

Desde el año 2003, el Museo Nacional en conjunto con el Instituto Nacional de Tecnología del Ministerio de Ciencia y Tecnología e Innovación (INT/MCTI), han realizado una serie de proyectos conjuntos de análisis de remanentes antiguos. Uno de los primeros estudios se hizo con la momia Sha-Amun-em-su, en 2009 (Belmonte, Santos y Brancaglion Jr., 2014). Así, mientras las excavaciones arqueológicas continúan en las ruinas del destruido Palacio São Cristóvão, la investigación en el área de la Egiptología también se puede llevar adelante a partir del acervo disponible en formato digital, resultado del proceso de escaneo de las momias y de los objetos realizado con anterioridad.

El Museo Nacional era la institución brasileña con el acervo egipcio más voluminoso y representativo. Además de este, la Fundação Eva Klabin (2020), que también se encuentra en Río de Janeiro, tiene algunos artefactos y se trata de un museo formado a partir de la colección privada de Eva Klabin, situada en su antigua casa (http:// evaklabin.org.br/). Antonio Brancaglion Jr. fue el responsable por la elaboración del catálogo del acervo egipcio de la Fundación, titulado Tempo, matéria e permanência: o Egito na Coleção Eva Klabin Rapoport (Brancaglion Jr., 2001). En dicho catálogo presenta las 37 obras egipcias del acervo. En 2001, una exposición titulada "Egipto faraónico: Tierra de los dioses", con la curaduría de Antonio Brancaglion y Elisabeth 
Délange, fue montada con las piezas del Museo del Louvre y de la Fundación Eva Klabin. En São Paulo, la exposición tuvo lugar en el Museo de Arte de São Paulo (MASP) y en Río de Janeiro, en la Casa França-Brasil. En el mismo año Brancaglion Jr. y Délange organizaron otra exposición con piezas del Louvre, esta vez en la FAAP - Fundação Armando Álvares Penteado. Con foco en el arte egipcio, tuvo como título "El arte egipcio en el tiempo de los faraones - acervo del Louvre".

\section{La Universidad de São Paulo}

Fuera de Río de Janeiro, el Museo de Arqueología y Etnología (MAE) de la Universidad de São Paulo es el que tiene el acervo más grande de la zona, el cual fue fruto de estudio de Antonio Brancaglion Jr. en su disertación de maestría titulada Arqueologia e Religião Funerária: a propósito do acervo egípcio do MAE (1993), con la tutoría de Haiganush Sarian. El Museo de Arqueología y Etnología fue creado en 1963 con el nombre de Museo de Arte y Arqueología de la Universidad de São Paulo y estaba ubicado inicialmente en el Departamento de Historia de la Facultad de Filosofía, Letras y Ciencias Humanas (FFLCH), y posteriormente fue trasladado a uno de los pisos del edificio de la residencia estudiantil de la USP, hasta que finalmente se estableció en un edificio situado al lado del ayuntamiento del campus universitario.

Según Antonio Brancaglion Jr. (1993), la colección egipcia del Museo de Arqueología y Etnología de la USP se constituyó, inicialmente, entre 1968 y 1978, con el acervo perteneciente a Franz Hermann Tapajós Hipp, quien heredó estos bienes del Sr. Hahn, un coleccionista de antigüedades alemán. El segundo mayor lote de piezas provino de la compra de la colección de Vera Bezzi Guida, entre 1967 y 1977, con la ayuda de la FAPESP (Fundação de Amparo à Pesquisa do Estado de São Paulo). Son 36 objetos que esta señora heredó de su abuelo, Tommaso Gaudencio Bezzi, ingeniero alemán responsable del diseño del Museo Paulista. Más tarde, se añadió a esta colección la tapa de un ataúd, que pertenecía a Tapajós Hipp, donación del Centro de Estudios Históricos Aphonso d'E. Taunay (CEHAT).

En 1989, con las reformulaciones estructurales de los museos de la USP, las colecciones arqueológicas fueron reunidas en su totalidad en el Museo de Arqueología y Etnología. Así, se destinaron a este museo las piezas egipcias que estaban en el Museo Paulista, también perteneciente a la USP, que pasó a albergar tan sólo la colección histórica, dedicada a la historia de Brasil. En 2005, con la quiebra del Banco Santos, la custodia de los objetos de dicho banco pasó al MAE. Entre estos variados objetos egipcios se cuenta una estela puerta-falsa que data del Imperio Antiguo (VI dinastía, ca. 2118 a.C.). Los artefactos egipcios del MAE no fueron fruto de una excavación científica, pues procedieron de colecciones particulares, construidas por intereses privados. Por lo tanto, la identificación de su procedencia se hace difícil. Sin embargo, se puede precisar que son objetos pertenecientes, en su mayoría, al mobiliario funerario de tumbas de particulares y son importantes como fuente de información acerca de las costumbres funerarias egipcias. Se destacan varios ushebtis, una momia de halcón del período grecorromano, el fragmento de un relieve que retrata a una de las hijas de Akenatón, faraón de la XVIII dinastía y un ushebti proveniente de la tumba real de Seti I (Brancaglion Jr., 1993).

Muchos alumnos de la USP interesados en Egiptología se han formado en el Museo de Arqueología y Etnología o en el Departamento de Historia. Aunque no haya ningún experto en el Antiguo Egipto en la universidad, el vínculo con la Arqueología Clásica y la Historia Antigua es el eje que guía dicha formación. Brancaglion tuvo como tutor a Haiganuch Sarian, quien trabajó en el Departamento de Antropología; más tarde migró al Museo de Arqueología y Etnología de la USP, donde se retiró, 
pero sigue desempeñándose como tutor en el Postgrado en Arqueología. Arqueóloga clásica perteneciente a la Escuela Francesa de Atenas y directora de investigación en el santuario de Hera en Delos, Grecia, Sarian fue pionera en los estudios clásicos en Brasil y realizó una gran contribución a la formación de los profesionales en Arqueología Clásica, además de ser también uno de los miembros fundadores de la SBEC - Sociedad Brasileña de Estudios Clásicos (Sarian, 2013).

Sarian fue una de las responsables por la organización de los volúmenes del Lexicon Iconographicum Mythologiae Classicae y ejerció una gran influencia sobre las generaciones de arqueólogos clásicos que la sucedieron, especialmente en relación con el análisis de la cerámica griega y los estudios iconográficos (Funari, 1997). Entre los investigadores de los que fue tutora Sarian se pueden mencionar a las profesoras Maria Isabel D’Agostino Fleming, Maria Beatriz Borba Florenzano y Elaine Veloso Hirata, que también trabajan en el Museo de Arqueología y Etnología. También formados por Haiganuch Sarian son los profesores Norberto Luiz Guarinello (del Departamento de Historia de la USP) y Pedro Paulo de Abreu Funari (UNICAMP - Universidad Estadual de Campinas). Aunque estos profesores tengan su área de especialidad en Grecia o Roma, también realizan tutorías en el área de Egipto romano o incluso del Egipto faraónico, como es el caso de Cássio de Araújo Duarte, tutoreado por Maria Isabel D’Agostino Fleming, y de José Roberto Pellini, actualmente profesor en la Universidad Federal de Minas Gerais (UFMG), quien fue alumno de Maria Beatriz Borba Florenzano.

En el Departamento de Historia de la USP hay tutorías de investigación en Egiptología realizadas por el asiriólogo Marcelo Rede. El profesor coordina el LAOP (2020), Laboratorio del Antiguo Oriente Próximo (http://www.usp.br/laop/), con investigaciones desarrolladas tanto en el área de la egiptología como de la asiriología. Su equipo organiza el "Coloquio Internacional: Procedimientos Interdisciplinarios aplicados al Antiguo Egipto y Oriente Próximo”, ya en su segunda edición. Marcelo Rede tuvo como tutor a Emanuel Bouzon, asiriólogo que fue profesor de la Pontificia Universidad Católica de Río de Janeiro (PUC-RJ).

La tutoría de la investigación en el área de arqueología clásica influyó mucho en la formación de los alumnos del Departamento de Antropología de la FFLCH y del Museo de Arqueología y Etnología de la USP. El método de análisis propio de la arqueología, con la producción de un catálogo o corpus con piezas del acervo que contiene sus datos de registro y de documentación, elementos de arqueometría, dibujos arqueológicos y la descripción de la pieza en sus más mínimos detalles, sirve de base a todo el trabajo arqueológico en cualquier campo específico del saber, a pesar de que se haya suscitado toda una polémica con respecto al carácter subjetivo del elemento descriptivo en arqueología, derivada fundamentalmente de las discusiones que planteó la arqueología post-procesual, todavía en la década de 1980, sobre la subjetividad del investigador en la interpretación de su objeto de estudio (Hodder, 1986; Vasques, 2005). La metodología del trabajo científico del arqueólogo se hizo presente, por lo tanto, en los estudios realizados en la Universidad de São Paulo, bajo la tutoría de los arqueólogos clásicos, muy a pesar de que la cuestión propiamente teórica no sea el punto fuerte de la Egiptología, un campo muy específico del conocimiento y a veces algo distante de los debates que implican las disciplinas de la antropología y la historia, por ejemplo.

\section{La Universidad Federal Fluminense}

Otro polo de formación en Egiptología en Brasil fue el establecido por el profesor Ciro Flamarion Santana Cardoso, en la Universidad Federal Fluminense (UFF), 
campus Gragoatá, en Niterói - RJ. Cardoso falleció en el 2013, pero sus exalumnos han dado continuidad a su legado. Cuando hacía su doctorado en París, entre 1967 y 1971, cuyo tema era acerca de la Guayana francesa durante el Antiguo Régimen, Ciro Flamarion comenzó a frecuentar la Escuela del Louvre, donde asistió a varios seminarios sobre la lengua y la arqueología egipcia. Fue alumno de Christiane Desroches-Noblecourt y tuvo clases de jeroglíficos con Paul Barguet, profesor de epigrafía egipcia en el Institut d'Egyptologie Victor Lorret, Université Lumière - Lyon 2 (Santos, 2012). Ciro Flamarion Cardoso era versátil y transitaba en diversas áreas del conocimiento, pero era notoria su competencia en la temática a la que se dedicaba. Llevó a cabo varios estudios sobre la esclavitud y sobre la Historia de América, su primera área de conocimiento y cuenta con publicaciones en el campo de la teoría y metodología de la Historia, Historia Económica y Social (Falcon, 2012). Notorio autor marxista, estuvo a la par de las transformaciones de esta línea teórica con el paso del tiempo, adaptándose a las nuevas discusiones de este campo de investigación.

Ciro Flamarion creó en 1988 el sector de Historia Antigua y Medieval en el Programa de Postgrado en Historia (PPGH) de la UFF e implementó el estudio de Egiptología en Brasil, en términos de la formación académica de estudiantes de maestría y doctorado en el área. Desde 1989, pasó a impartir la asignatura de Lengua Egipcia para sus alumnos del PPGH. En los años 80 del siglo XX publicó el libro O Egito Antigo (Cardoso, 1982), que se convirtió en una referencia para los estudiantes del grado de la carrera de Historia. Los libros de Ciro Flamarion Cardoso aún hoy son una referencia para los estudiantes universitarios, dada la poca disponibilidad de publicaciones especializadas en portugués. Entre estos, citamos: Trabalho compulsório na Antiguidade: ensaio introdutório e coletânea de fontes primárias (Cardoso, 1984), Antiguidade Oriental: política e religião (Cardoso, 1990), Sete Olhares sobre a Antiguidade (Cardoso, 1994), Deuses, Múmias e Ziggurats: uma comparação das religiões antigas do Egito e da Mesopotâmia (Cardoso, 1999) y Sociedades do Antigo Oriente Próximo (Cardoso, 2005). Ciro Flamarion Cardoso también organizó el libro Modo de Produção Asiático: nova visita a um velho conceito (Cardoso, Bouzon y Tunes De Melo, 1990). Y, además, llegó a preparar una gramática del Egipcio Medio y más adelante también del Neoegipcio para utilizarlas en sus clases, pero, por desgracia, nunca llegó a publicarlas (Santos, 2012).

La posición teórica marxista de Ciro Flamarion Cardoso guía todo su pensamiento y su obra, lo que constituye una gran contribución de este intelectual para la formación en Egiptología en Brasil. Hay pocos historiadores marxistas, actualmente, en la academia brasileña. Sin embargo, es saludable la convivencia de pensadores con pensamientos divergentes en las universidades, consideradas como un espacio de debate, de intercambio de ideas y de crecimiento intelectual. El rigor científico de Ciro Flamarion se hacía presente en su posición teórica, pero especialmente también en la metodología que empleaba en el análisis de las fuentes: lograba conciliar sus estudios marxistas con un método de análisis de fuentes basado en la sociología genética de Lucien Goldmann y en el estructuralismo lingüístico de Tzvetan Todorov (Funari, 1995). Un brillante ejemplo de esta aplicación reside en su análisis de las "Memorias de Sanehet", texto también conocido como "Historia de Sinuhé", un cuento egipcio que data del Imperio Medio, probablemente de la XII dinastía (ca. 1985-1795 a.C.). El análisis de este cuento constituye uno de los capítulos de su libro Sete Olhares sobre a Antiguidade, titulado Ideologia e literatura no antigo Egito: o conto de Sanehet (Cardoso, 1994). La preocupación por las cuestiones teóricometodológicas aplicadas al campo más general de los estudios históricos $-\mathrm{y}$ no sólo de la Egiptología - orientaba también las actividades de Cardoso. Una de sus últimas obras fue la organización del libro Semiótica do espetáculo: um método para a História (Cardoso y Beltlrão da Rosa, 2013). 
En la UFF fue uno de los miembros fundadores del CEIA (2020) - Centro de Estudios Interdisciplinarios de la Antigüedad (http://www.ceia.uff.br) en 1998, laboratorio que reunía profesores del Departamento de Historia y de Letras Clásicas y Vernáculas, además de investigadores de otras universidades y estados. Después de la muerte de Cardoso, se fundó en 2013, el Grupo de Estudos Kemet: História e Arqueologia do Egito Antigo (GEKEMET), gestionado por Beatriz Moreira da Costa, estudiante de doctorado del programa de postgrado en Historia de la UFF, bajo la guía de Alexandre Santos de Moraes, quien a su vez tuvo como tutor a Cardoso en su tesis de doctorado sobre los poemas homéricos.

El profesor Ciro Flamarion Cardoso graduó a muchos alumnos, profesores universitarios hoy en día. Entre ellos, el también profesor de la UFF, del campus de Goytacazes, Júlio César Mendonça Gralha, quien dirige el NEHMAAT (2010) - Núcleo de Estudios en Historia Medieval, Antigua y Arqueología Transdisciplinaria (http://www.nehmaat.uff. br/) y Nely Feitoza Arrais, que da clases en el Instituto de Educación de la Universidad Federal Rural de Rio de Janeiro, pero que ha cotutoreado disertaciones y tesis en el área de Egiptología en el Departamento de Historia de la UFRRJ. Otro exalumno de Ciro Flamarion que está en la UFRRJ es el profesor Luís Eduardo Lobianco, especialista en el Egipto romano.

\section{Otros polos}

En el sur de Brasil podemos destacar la existencia de dos exalumnos del profesor Ciro Flamarion. Son ellos Moacir Elias Santos y Liliane Cristina Coelho. Ambos dan clases en la UNIANDRADE, una universidad privada de Curitiba y trabajan juntos en el Museu Egípcio da Rosa Cruz y también en el Museu de Arqueologia Ciro Flamarion Cardoso, que se encuentra en Ponta Grossa - PR, formado por réplicas de piezas egipcias y con una función educativa enfocada en la Enseñanza Primaria, Secundaria y de Bachillerato.

En Rio Grande do Sul se destaca Katia Maria Paim Pozzer, especialista en Asiriología, quien es profesora de la Universidad Federal de Rio Grande do Sul, en el Departamento de Artes Visuales y que se desempeña como tutora en el área de Historia Antigua (incluyendo el Antiguo Egipto) en el Programa de Postgrado en Historia de dicha universidad. En tanto, en la Pontificia Universidad Católica de Rio Grande do Sul (PUCRS) da clases Margaret Bakos, que se graduó en el área de Historia de Brasil, pero se especializó en estudios de Egiptomanía en Brasil (Bakos y Funari, 2008).

En la región centro-oeste de Brasil se destacó Emanuel de Oliveira Araújo (2000), quien era un especialista en arqueología bíblica y en las relaciones entre los egipcios y los hebreos. Fue profesor en el Departamento de Historia de la Universidad de Brasilia (UnB), de 1968 a 1971, cuando tuvo que salir por razones políticas, en la época en que Brasil vivía el período de la dictadura militar. Fue reincorporado a la universidad en 1989. Inicialmente Araújo se graduó en dramaturgia y literatura dramática en la Universidad Federal de Bahía, pero tuvo como tutor al helenista portugués Eudoro de Souza, lo que le proporcionó su formación erudita en griego, latín y hebreo. Su libro Escrito para a eternidade: a literatura no Egito faraônico, publicado en el año 2000, justo después de la muerte del autor, fue traducido directamente del egipcio al portugués. Su objetivo era proporcionar a los estudiantes brasileños contacto con la literatura producida en el Egipto faraónico y sigue siendo hoy en día una obra de referencia para los estudiantes universitarios brasileños.

En el noreste de Brasil, así como en la región norte, el área de Historia Antigua tiene un desarrollo todavía incipiente, pero ya ha mostrado frutos con los concursos que se 
realizaron principalmente en los últimos dieciséis años, período en el que se contrató a profesores expertos en el área.

En la Universidad Federal de Sergipe se desempeñó en el sector de Arqueología, del 2015 al 2017, José Roberto Pellini, actualmente miembro del Departamento de Arqueología y Antropología de la Universidad Federal de Minas Gerais. Pellini es responsable del proyecto Amenenhet, de excavación, restauración y conservación de las tumbas tebanas TT123 y TT368, en Lúxor, Egipto. Pellini contó con la tutoría de la profesora Maria Beatriz Borba Florenzano, del Museo de Arqueología y Etnología de la USP. El programa de postgrado en Historia de la Universidad Federal de Paraíba (UFPB) a partir de la llegada, en 2015, de la profesora Priscilla Gontijo Leite, doctora en el área de Mundo Antiguo por la Universidad de Coímbra, también pasó a desarrollar investigaciones en el área de Historia Antigua y Egiptología.

En Natal, capital del estado de Rio Grande do Norte, Marcia Severina Vasques creó, en 2009, junto con los alumnos, monitores y becarios de iniciación científica, el MAAT - Núcleo de Estudo de História Antiga, que ha actuado en las áreas de investigación, extensión y enseñanza en la Universidad Federal de Rio Grande do Norte - UFRN. Graduada en arqueología por el Museo de Arqueología y Etnología de la USP, con la tutoría de la profesora Maria Isabel D’Agostino Fleming, el área de investigación de la profesora es el Egipto Romano. Por el interés de los alumnos en el estudio de la Egiptología, las investigaciones realizadas en el ámbito del estado de Rio Grande do Norte se han direccionado al período faraónico. En esta área se destacan las tesis de maestría de Keidy Narell y Costa Matias titulada Cartografias do Além: o mundo dos vivos e o universo dos mortos no Egito Antigo (Matias, 2016) y de Arthur Rodrigo Fabrício (2016) sobre O complexo de culto real de Ramessés III: espaço e memória na XX Dinastia do Egito Antigo.

La región norte carece aún más de especialistas en el área. Pero la Universidad Federal de Amazonas (UFAM) logró recientemente implementar su programa de postgrado en Historia, nivel de maestría (2018). En su equipo de profesores se desempeña Joana Campos Clímaco, cuya tesis de doctorado fue sobre la Alejandría romana, área de la Arqueología Clásica en diálogo permanente con la Egiptología.

Aunque el foco de la investigación en Egiptología sea el eje Río-São Paulo, o sea, la región sureste de Brasil, con la expansión de las universidades públicas y de los cursos de postgrado, maestrías y doctorados, hacia otras áreas, como la noreste, la tendencia es que surjan varios centros de investigación en el país, lo que demuestra que la inversión en las universidades es un factor generador de desarrollo tecnológico, humano e intelectual.

\section{Mapa de la Egiptología en Brasil}

En virtud de lo expuesto arriba podemos considerar que la formación en Egiptología en Brasil reconoce, fundamentalmente, dos orígenes: la formación en Arqueología (derivada de la Arqueología Clásica) y la formación en Historia Antigua.

La Figura 1 muestra los polos de desarrollo de la investigación sobre el Antiguo Egipto en Brasil, según los programas de postgrado, el área de la formación del profesor y la temática de investigación y/o en la cual es tutor. Se observa el foco original, constituido por la región sureste, donde se encuentran las ciudades de Río de Janeiro y de São Paulo, otras áreas como la región sur (Paraná y Rio Grande do Sul) y los polos de expansión para la región noreste del país (Rio Grande do Norte y Paraíba) y el norte (Amazonas). 


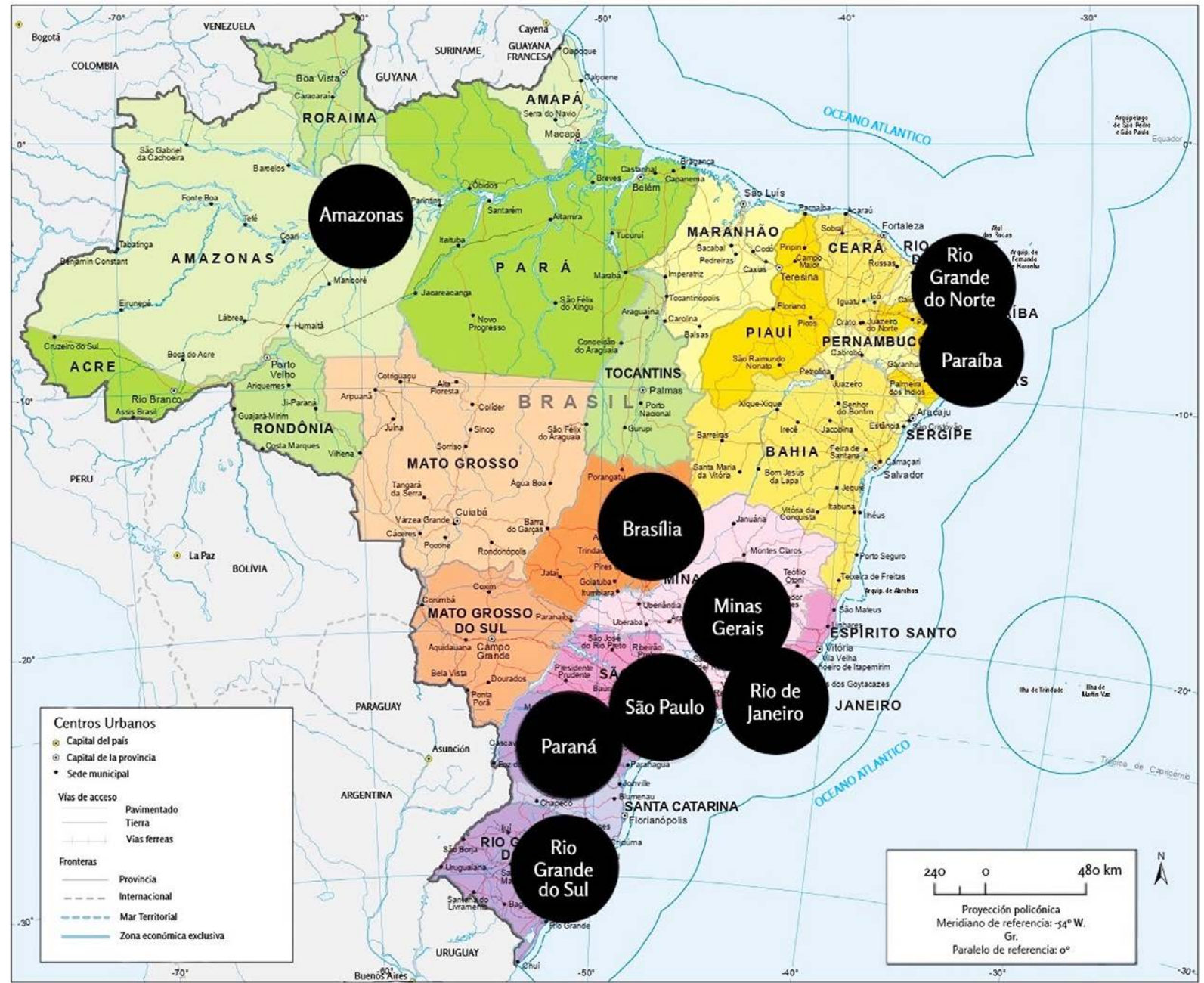

Figura 1. Mapa de distribución en Brasil de las investigaciones sobre el Antiguo Egipto. Fuente: adaptado de IBGE (2019).

\section{Consideraciones finales}

Al presentar el desarrollo de la Egiptología en Brasil nos propusimos rastrear sus orígenes y mapear los polos de difusión del conocimiento científico en este campo de estudio a finales del siglo XX y principios del XXI. En general, al tratar la Egiptología brasileña, es imposible no abordar la familia imperial brasileña y el interés que la nobleza europea (y la brasileña) tenía por las civilizaciones antiguas, incluso Egipto. Fue como consecuencia de las exploraciones arqueológicas en Egipto realizadas por aventureros como Giovanni Battista Belzoni que los primeros artefactos y momias egipcias llegaron a Brasil y fueron adquiridos por el emperador D. Pedro I. Este interés prosiguió, sobre todo con el segundo Pedro, hijo del primero, gran admirador de las artes y de las ciencias, considerado el primer egiptólogo brasileño debido a su gran erudición e interés por el estudio de la escritura jeroglífica.

La ciudad de Río de Janeiro se convirtió en un polo de los estudios egiptológicos por haber sido la sede del Imperio brasileño y la residencia oficial de la familia real que, cuando se retiró del país al exilio, después de la Proclamación de la República en 1889, dejó sus pertenencias y colecciones particulares en el país, las cuales pasaron a formar parte del Museo Real, luego trasladado al palacio São Cristóvão, ubicado en la Quinta da Boa Vista. Río de Janeiro fue capital de Brasil hasta la construcción de Brasilia, en la 
década de 1960, un proyecto concretizado durante la gestión del presidente Juscelino Kubitscheck de Oliveira. Dos universidades fueron cruciales en esta formación en Egiptología: la Universidad Federal de Río de Janeiro, a cuyo cargo quedó el Museo Nacional, y la Universidad Federal Fluminense. La primera, a pesar de contar con un acervo importante, sólo desarrolló efectivamente la investigación en el área y la formación de estudiantes de postgrado después de la llegada de Antonio Brancaglion Jr., en 2002. En tanto, la segunda amplió la investigación sobre Egiptología con el ingreso en la universidad de Ciro Flamarion Santana Cardoso, en 1979.

Otra ciudad importante en la formación de investigadores es São Paulo, con la mayor universidad del país, la USP - Universidad de São Paulo. Fue de la Facultad de Filosofía, Letras y Ciencias Humanas (FFLCH) y del Museo de Arqueología y Etnología (MAE) de la USP, a partir del núcleo de arqueología clásica, de la que salieron los investigadores que dieron continuidad a la investigación en el área de la Egiptología. Entre ellos se pueden citar al propio Brancaglion Jr. Actualmente, los estudios de Egiptología se están expandiendo a otras regiones del Brasil, debido principalmente al estímulo a los programas de postgrado de las universidades públicas federales que se produjo en la última década. El diagnóstico es positivo, aunque la Egiptología haya sufrido un inmenso trauma con el incendio ocurrido en el Museo Nacional en septiembre de 2018, que tuvo como resultado la destrucción casi completa de su acervo. Con las excavaciones arqueológicas en marcha en las ruinas del palacio, algunas piezas fueron recuperadas. Sin embargo, los investigadores han continuado sus estudios a partir de las copias digitalizadas del acervo original.

Para terminar este breve balance sobre la Egiptología en Brasil, menciono los retos de la investigación en el área, así como nuestras expectativas positivas:

»Entre los problemas y desafíos que se presentan tenemos como principales: la falta de un curso sobre la lengua egipcia, que, cuando existe, se limita a la relación alumnotutor; la escasez de bibliografía cualificada, a pesar de que la accesibilidad a las obras ya haya mejorado mucho con la llegada de internet y la disponibilidad para adquirir los libros y las publicaciones como e-books; la dificultad para tener acceso a la documentación material (excepto quienes estudian el acervo de los museos existentes en el país) y la falta de un eje guía como un Instituto de Egiptología, ya que los alumnos se gradúan muchas veces en áreas diferentes del saber (en Historia, Arqueología o Letras).

» Entre las expectativas positivas resalto: el hecho de estudiar Egiptología en Brasil hace que podamos observar nuestro campo de estudio y analizar nuestras fuentes desde la perspectiva de la periferia, es decir, disponer de una visión distanciada de la europea, a menudo vinculada a una larga tradición de estudios de la que es difícil librarse; además, existe un creciente interés por la Egiptología en Brasil alentado por los estudios de Historia de África, que buscan considerar la africanidad de la antigua civilización egipcia, en general poco estudiada por la Egiptología, aspecto importante para una gran parte de la población brasileña, formada por descendientes de africanos.

» Por último, podemos pensar como una forma de solución para nuestros futuros desafíos trabajar con vistas a crear redes de investigación que integren no sólo el país, sino también América del Sur, ya que al parecer todos compartimos las mismas dificultades. Brasil, durante mucho tiempo, se mostró aislado de sus vecinos, ya sea por su tamaño continental o por la barrera lingüística. Pero creo que la consolidación de redes de investigación se muestra esencial en los días de hoy y es una de las políticas actuales de la CAPES, Coordenação de Aperfeiçoamento de Pessoal de Nível Superior, órgano responsable de gestionar los postgrados en Brasil. 


\section{Agradecimientos}

Agradezco a Francisco Zaragoza por la traducción del texto al español y a Pedro Hugo Canto por la confección del mapa. También agradezco a los revisores externos por sus valiosos comentarios, que enriquecieron el contenido del manuscrito original. 


\section{Q Referencias citadas}

》Araújo, E. (2000). Escrito para a eternidade: a literatura no Egito faraônico. Brasília: UnB.

"Bakos, M. (2009). Fatos e mitos do Antigo Egito. Porto Alegre: EDIPUCRS.

» Bakos, M. y Funari, R. dos S. (2008). História da Tradição Clássica no Brasil nos séculos XIX e XX. Egito Antigo no Brasil: Egiptologia e egiptomania. En A. L. Chevitarese, G. Cornelli y M. A. de O. Silva (Eds.), A Tradição Clássica e o Brasil (pp. 149-157). Brasília: Fortium.

" Belmonte, S., Santos, J. R. L. dos y Brancaglion Jr., A. (2014). Tecnologias tridimensionais aplicadas em pesquisas arqueológicas em múmias egípcias. En A. Brancaglion Jr., S. Belmonte y J. Lopes (Eds.), SEMNA - Estudos de Egiptologia I (pp. 47-63). Rio de Janeiro: Seshat - Laboratório de Egiptologia do Museu Nacional.

» Brancaglion Jr., A. (1993). Arqueologia e Religião Funerária: a propósito do acervo egípcio do MAE. (Tesis de Maestría inédita), Universidad de São Paulo, Brasil.

" Brancaglion Jr., A. (2001). Tempo, matéria e permanência. O Egito na coleção Eva Klabin Rapaport. Fundação Eva Klabin Rapaport. Rio de Janeiro: Casa da Palavra.

" Brancaglion Jr., A. (2005). Revelando o passado: estudos da coleção egípcia do Museu Nacional. En F. de S. Lessa y R. Bustamante (Eds.), Memória \& Festa (pp. 75-80). Rio de Janeiro: Mauad.

" Brancaglion Jr., A. (2013). Um Egito ainda desconhecido: coleções e colecionismo no Brasil. Revista Tempo Brasileiro, 193, abril-junho, 39-56.

" Cardoso, C. F. S. (1982). O Egito Antigo. São Paulo: Brasiliense.

"Cardoso, C. F. S. (1984). Trabalho compulsório na Antiguidade: ensaio introdutório e coletânea de fontes primárias. Rio de Janeiro: Graal.

"Cardoso, C. F. S. (1990). Antiguidade Oriental: política e religião. São Paulo: Contexto.

»Cardoso, C. F. S., Bouzon, E. y Tunes de Melo, C. M. (1990). Modo de produção asiático: nova visita a um velho conceito. Rio de Janeiro: Campus.

" Cardoso, C. F. S. (1994). Sete olhares sobre a Antiguidade. Brasília: UnB.

" Cardoso, C. F. S. (1999). Deuses, Múmias e Ziggurats: uma comparação das religiões antigas do Egito e da Mesopotâmia. Porto Alegre: EDIPUCRS.

»Cardoso, C. F. S. (2005). Sociedades do Antigo Oriente Próximo. São Paulo: Ática.

»Cardoso, C. F. S. y Beltrão da Rosa, C. (2013). Semiótica do espetáculo: um método para a História. Rio de Janeiro: Apicuri/FAPERJ.

» Carlan, C. U. y Funari, P. P. A. (2010). Patrimônio e Colecionismo: algumas considerações. Revista Magistro, 1(1), 16-24.

»CEIA (2020). Centro de Estudos Interdisciplinares de Antiguidade. Instituto de Letras - Departamento de Letras Clássicas e Vernáculas. Universidade Federal Fluminense, http://www.ceia.uff.br (Acceso: 01 de julio, 2020).

»Donadoni, S., Curto, S. y Roveri, A. M. D. (1990). Egipto: del Mito a la Egiptología. Milán: Fabbri.

》Fabrício, A. R. (2016). O complexo de culto real de Ramessés III: espaço e memória na XX Dinastia do Egito Antigo. (Tesis de Maestría inédita), Universidad Federal de Rio Grande do Norte, Brasil. 
" Falcon, F. J. C. (2012). Ciro Flamarion Santana Cardoso - uma memória em vários tempos. En S. R. de Araújo y A. C. C. Lima (Eds.), Um combatente pela História: Professor Ciro Flamarion Cardoso (pp. 29-42). Rio de Janeiro: Vício de Leitura.

» Funari, P. P. A. (1995). Ciro Flamarion Cardoso. Sete Olhares sobre a Antiguidade. Crítica Marxista, 2, 171-172.

» Funari, P. P. A. (1997). European archaeology and two Brazilians offsprings: classical archaeology and art History. Journal of European Archaeology, 5(2), 137-148.

» Fundação Eva Klabin (2020). Casa Museu Eva Klabin, http://evaklabin.org.br (Acceso: 15 de julio, 2020).

" Hodder, I. (1986). Interpretación en Arqueología: corrientes actuales. Barcelona: Crítica.

» IBGE (2019). Território. Divisão política, Diretoria de Geociências, Coordenação de Cartografia, Instituto Brasileiro de Geografia e Estatística, https://brasilemsintese.ibge. gov.br/territorio/divisao-politica.html (Acceso: 14 de marzo, 2019).

》Ikram, S. (2009). Ancient Egypt. An Introduction. Cambridge: Cambridge University Press.

» LAOP (2020). Laboratório do Antigo Oriente Próximo, Universidad de São Paulo, http:// www.usp.br/laop (Acceso: 01 de julio, 2020).

"Lemos, R. de S. (2014). Introdução: Panorama da Egiptologia no Brasil (1827-2014 e além). En R. de S. Lemos (Ed.), O Egito Antigo: novas contribuições brasileiras (pp. 20-37). Rio de Janeiro: Multifoco.

》 Matias, K. N. C. (2016). Cartografias do Além: o mundo dos vivos e o universo dos mortos no Antigo Egito. (Tesis de Maestría inédita), Universidad Federal de Rio Grande do Norte, Brasil.

" Museu Nacional (2020). Museu Nacional apresenta balanços após um ano do incêndio, Museu Nacional, Universidade Federal do Rio de Janeiro, http://www.museunacional. ufrj.br/destaques/balan\%C3\%A70_resgatehtml.html (Acceso: 21 de septiembre, 2019).

" NEHMAAT (2010). Núcleo de Estudos em História Medieval, Antiga e Arqueologia Transdisciplinar, Universidade Federal Fluminense, http://www.nehmaat.uff.br/ (Acceso: 15 de julio, 2020).

» Said, E. (1990). Orientalismo: o Oriente como invenção do Ocidente. São Paulo: Cia das Letras.

"Santos, M. E. (2012). Estelas, hieróglifos e Ciro Flamarion Cardoso: uma contribuição ao desenvolvimento da Egiptologia no Brasil. En S. R. de Araújo y A. C. C. Lima (Eds.), Um combatente pela História: Professor Ciro Flamarion Cardoso (pp. 105-123). Rio de Janeiro: Vício de Leitura.

"Sarian, H. (2013). Os caminhos de uma Arqueologia Clássica no Brasil. En J. G. C. Grillo y P. P. A. Funari (Eds.), Os caminhos da Arqueologia Clássica no Brasil (pp. 19-30). São Paulo: Annablume.

"Schwarcz, L. M. (1998). As barbas do imperador. D. Pedro Il, um monarca nos trópicos. São Paulo: Cia das Letras.

"Schwarcz, L. M. (2009). De olho em D. Pedro Il e seu reino tropical. São Paulo: Claro Enigma.

》SESHAT (2020). SESHAT. Laboratório de Egiptologia do Museu Nacional, Universidade Federal do Rio de Janeiro, https://seshat.museunacional.ufrj.br/ (Acceso: 15 de julio, 2020).

"Silva, T. R. da (2017). Tropical Egypt: The Development of Egyptology in Brazil and its Future Challenges. En C. Langer (Ed.), Global Egyptology: Negotiations in the Production of Knowledges on Ancient Egypt in Global Contexts (pp. 161-172). London: Golden House Publications. 
"Trigger, B. (2004). História do Pensamento Arqueológico. São Paulo: Odysseus.

"Vasques, M. S. (2005). Crenças funerárias e identidade cultural no Egito Romano: máscaras de múmia. (Tesis Doctoral inédita), Universidad de São Paulo, Brasil. 